\title{
Optical and protective properties of different type diamond and diamond-like carbon films
}

\author{
T. V. Semikina, A. N. Shmyryeva \\ National Technical University of Ukraine "KPI» \\ Pr. Pobedy 37, build. 12, \\ 02056 Kiev, Ukraine \\ e-mail:semikina@ee.ntu-kpi.kiev.ua,semikina@edd.ntu-kpi.kiev.ua
}

\begin{abstract}
Comparative analyses of diamond and diamond like carbon film optical properties prepared by laser and chemical vapor deposition methods are represented in this work. It was obtained that DF and DLC films have optical properties enabling to use them as antireflection coatings for solar cells. Application of both film types as protective antireflection coatings for solar cells operating under Earth conditions has enabled to increase solar cell efficiency up to $19.5 \%$. Solar cell degradation characteristics when using DLC coatings under space radiation conditions are represented. It was obtained that application of DLC films prepared by chemical deposition method at self-bias voltage $-300 \mathrm{~V}$ has allowed to considerably reduce short-circuit current degradation as compared with that of another protective coatings.
\end{abstract}

Keywords: diamond and diamond like carbon films, solar cell, degradation characteristics.

Paper received 10.07.01; revised manuscript received 17.10.01; accepted for publication 12.12.01.

\section{Introduction}

The synthesis and investigation of new band gap materials is one of the leading directions in electronics. It is concerned with necessity to develop the coatings for optics, elaborate new photodetectors in ultraviolet range, develop new functional layers for electronic devices. That is why the big attention is given to deposition and researching of diamond (DF) and diamond like carbon film (DLC) properties which, besides large values of their band gaps, have also properties making these films especially attractive for application in electronics. There are high radiation and chemical resistance, high thermal stability and thermal conductivity. But the most important and interesting is the possibility to control film properties during deposition process via changing technological regimes. DF and DLC films can be obtained by all known vacuum methods. We could synthesize the films with various properties in dependence on deposition method. Even within one technology deposition method, changing only one technological parameter, we can obtain films from soft polymer-like compound to the hard diamond-like carbon ones. The laser and chemical vapor deposition methods are more widely spread and well-devel- oped as film-synthesizing methods. We studied optical and protective properties of DF and DLC films prepared by these two methods for their future application as antireflection and protective coatings for solar cells.

\section{The deposition technology and experiments}

The DLC films were deposited by r.f. glow discharge in a parallel plate reactor [1]. The r.f. power (13.56 MHz) was applied to the lower electrode. The DLC films of 0.4-0.6 $\mu \mathrm{m}$ thickness were deposited on silicon substrates using methane decomposition in the working gas mixture with nitrogen and hydrogen.

The DF with thicknesses $0.4-1.0 \mu \mathrm{m}$ were deposited on silicon and silica substrates by laser sputtering of carbon target using the equipment of pulse laser deposition "Kvant" [2]. The laser power density was changed from $5 \cdot 10^{7}$ up to $5 \cdot 10^{10} \mathrm{~W} / \mathrm{cm}^{2}$, and substrate temperature during the process deposition was changed from 298 to $673 \mathrm{~K}$.

Film transmittance and reflection spectra were measured in the wavelength range $200-800 \mathrm{~nm}$. The spectrophotometer «SPECORD UF VIS» was used for this investigation. The reflection spectra were measured using a stand- 


\section{T. V. Semikina, A. N. Shmyryeva: Optical and protective properties ...}

ard reflection attachment. The angle of light incidence on the sample was $20^{\circ}$. The refraction coefficient was measured by the ellipsometer LEF-3M via polarization angle determination, measurement accuracy of which does not exceed three arc minutes.

The solar cell samples were tested under high energy electron and proton fluxes with energy $10 \mathrm{MeV}$ on microtron M30 (Institute for Electron Physics, Uzgorod), combined effect of low energy electrons and protons, $E=170 \mathrm{keV}$ (Physics-and-Technical Institute of Low Temperatures, Kharkov) with different equivalent orbit staying (on orbits $670,8000,36000 \mathrm{~km}$ ). The pieces of honeycomb structure silicon solar cells moduli were tested on proton flux exposure at the Scientific Center "Institute for Nuclear Researches", NASU, Kyiv. The proton flux was changed from $3 \cdot 10^{10}$ to $3 \cdot 10^{13} 1 / \mathrm{cm}^{2}$ at the energy value $20 \mathrm{MeV}$.

\section{DF and DLC optical properties}

Optical absorption and reflection researches allow getting information about such basic optical parameters of the materials as an absorption coefficient, coefficient of refraction, band gap. At first, we demonstrate the DF optical properties prepared by laser deposition method. The high and low resistance DF were deposited on silica substrates with sizes of $10 \times 20 \mathrm{~mm}^{2}$. Film transmission spectra were normalized on substrate transmission spectra. The film spectra had no pronounced absorption edge, and film transmission was increased at decreasing wave number (Fig.1). Such spectrum behavior is typical for DF and stems from the electron structure of these materials [3]. The DF spectra of both types differ sufficiently: the higher resistance films have a higher transmission coefficient in comparison with the low resistivity ones in all researched spectral range. The increasing absorption coefficient in low resistance DF is possibly caused by a larger part of $\mathrm{sp}^{2}$ coordinative bonds in comparison with content of $\mathrm{sp}^{3}-$ bonds.

DF absorption coefficient $\alpha$ estimation was fulfilled directly from transmission spectrum using the formula (1) [4]:

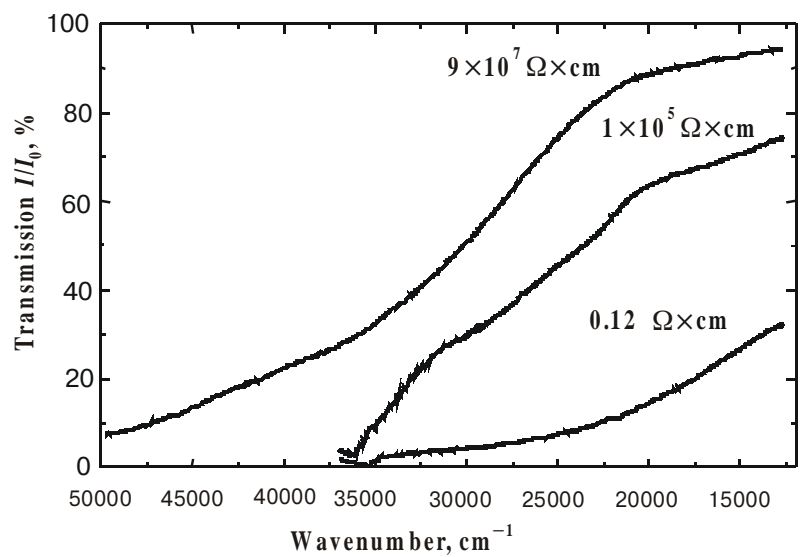

Fig.1. Transmissions spectrum of diamond films with different specific resistances $\alpha(\lambda)=d^{-1} \ln \left(I_{0}(\lambda) / I(\lambda)\right)$

where $d$ is a film thickness, $I_{0}(\lambda)$ is an intensity of illumination that passes through substrates without DF, $I(\lambda)$ - intensity of illumination that passes through substrates with DF. The accuracy of absorption coefficient determination using this method was $10 \%$.

The absorption coefficient of both types DF dependence on wavelength is represented on Fig.2. These transmission spectra of DF with $\rho=9 \cdot 10^{7} \Omega \cdot \mathrm{cm}, \rho=1 \cdot 10^{5} \Omega \cdot \mathrm{cm}$ and $\rho=0.12 \Omega \mathrm{cm}$ were else normalized relatively transmission substrate spectrum. The DF band gap $E_{g}$ was calculated from DF absorption coefficient dependence on wavenumber using the formula:

$(\alpha h v)^{1 / 2}=B\left(E_{g}-h v\right)$

where $h v$ is a quantum energy, $B$ is a constant, $\alpha$ is an absorption coefficient of the film.

The plot of dependences $(\alpha h v)^{1 / 2}$ versus $h v$ (the Tauc plot) using for investigated DF with different specific resistance band gap determination is represented in Fig. 3. We can see that film spectra have "tails" that are caused by carbon phase presence. Calculation of band gap values by the formula (2) for diamond film phase results in $4.0-4.35 \mathrm{eV}$, while for carbon phase in $1.2-2.2 \mathrm{eV}$.

The reflection spectra of high and low resistance DF (Fig. 4) demonstrate weak reflection of light for both DF types in the range $200-800 \mathrm{~nm}$. We observe the monotonous decrease of reflection coefficient from 0.25 to 0.08 at decreasing wavelengths for low resistance films and from 0.1 to 0.03 for high resistance films. From the viewpoint of solar cell application, the results of optical characteristics investigation of diamond films deposited by laser sputtering demonstrate that these synthesized films can be shown as initial material for converters with sensibility in ultraviolet as well as in visible spectral ranges.

The next type of the films were diamond like carbon films prepared by chemical deposition method at two different self-bias voltages $U_{\text {sel }}$ : 1) soft DLC films prepared at $\left.U_{\text {sel }}=-100 \mathrm{~V}\left(\mathrm{DLC}_{\mathrm{soft}}\right) ; 2\right)$ hard DLCat $U_{\text {sel }}=-300 \mathrm{~V}\left(\mathrm{DLC}_{\mathrm{hard}}\right)$.

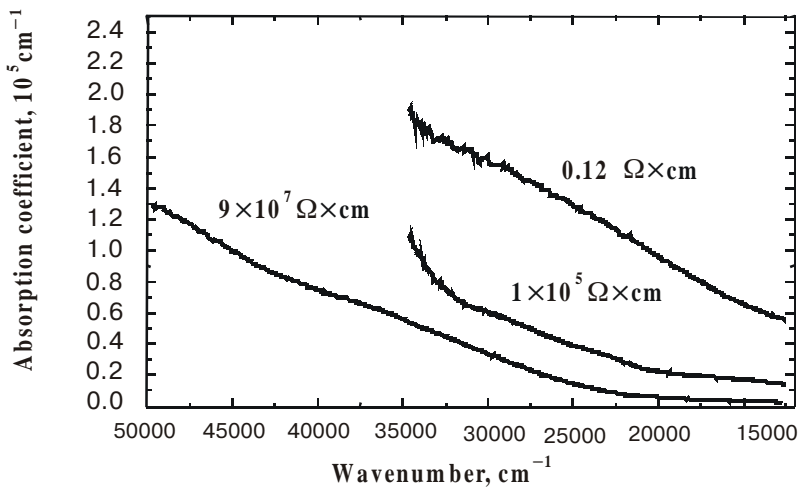

Fig.2. Absorption coefficient of diamond films with different specific resistance as dependent on wavenumber. 


\section{T. V. Semikina, A. N. Shmyryeva: Optical and protective properties ...}

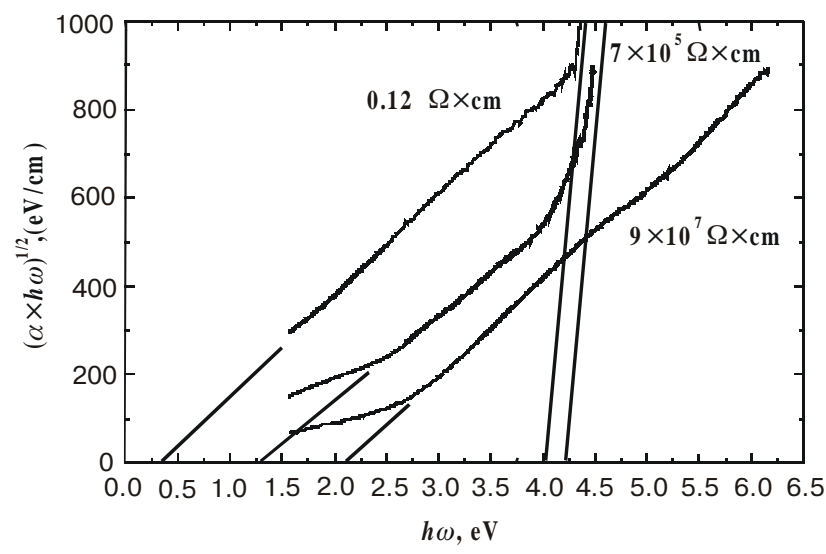

Fig.3. Tauc plot of DF with different resistivity

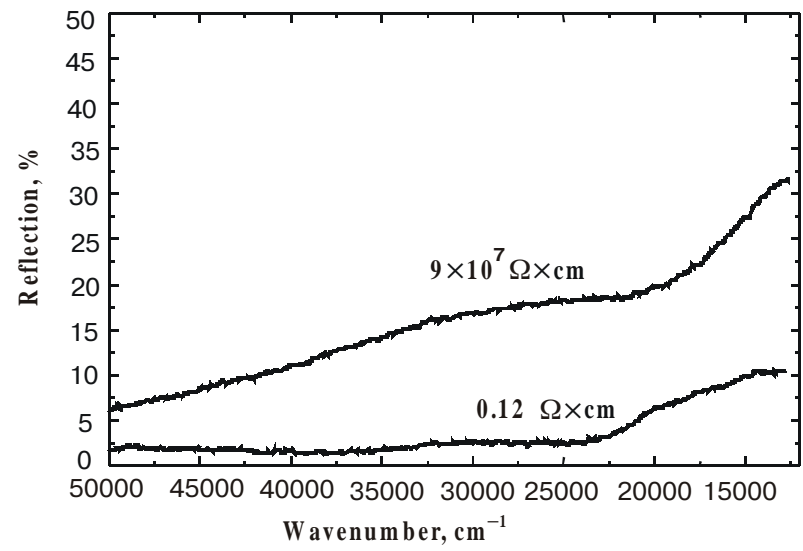

Fig.4. Reflection spectrum of diamond films with different specific resistance

It is known that self-bias voltage is one of the most important technological parameters, changing which we got films with hardly distinguished properties. During $\mathrm{DLC}_{\text {soft }}$ optical properties investigation made in the Institute of Semiconductor Physics (Kiev) [5,6], it was obtained that at selfbias voltage variation we can obtain amorphous DLC with refraction coefficient $n$ from 1.6 to 2.2. When we increase the methane content in gas mixture and decrease the selfbias voltage, we deposit the films with small refraction coefficient magnitude. The optical band gap films with $n=1.6$ is $3.3 \mathrm{eV}$. At small self-bias voltage that does not exceed $300 \mathrm{~V}$, there is a process of soft carbon films formation with a relatively high value of the band gap $\left(E_{g}>3 \mathrm{eV}\right)$. With increasing $r$. f. voltage, film-formation process with larger content of carbon-carbon bonds takes place, and these films transform into diamond like carbon films DLC $\mathrm{C}_{\text {hard }}$ with hydrogen concentration up to $20 \%$. The optical band gap in this case is not more than $2.0 \mathrm{eV}$. The investigation of $\mathrm{DLC}_{\text {hard }}$ [7] demonstrated that addition of $10-15 \%$ nitrogen to gas mixture enables to obtain the films with $n=1.9$ that is optimum value for applying these films as antireflection coatings on silicon.
So, we can obtain the DLC films with previously fixed optical properties due to possibility to change special technological conditions that were found and investigated.

\section{Antireflection and protective properties for solar cells}

For getting information about possibility to use investigated films as antireflection coatings the DF and DLC films were deposited on silicon solar cells. Deposition DF with thickness of $0.1 \mu \mathrm{m}$ on silicon cell working surface allows to increase the short circuit current and efficiency by $40 \%$ in comparison with non-covered solar cells. The obtained results are mainly determined by the surface blooming effect due to reflection coefficient decreasing in the operative wavelength range. From reflection spectra of the solar cells in Fig. 5, there is the result that $0.1 \mu \mathrm{m}$ DF coating leads to reflection coefficient decreasing in the solar cell operative range by 3.5 times for the short wave range 460-600 nm. Hence, DF deposition provides an increase of the solar cell efficiency due to blooming effect. Besides, the formed coating has high mechanical and chemical resistance. From our results follows the doubtless prospects of DF application as solar cell antireflection coatings.

From the results for DLC, it was obtained that solar cell reflection coefficient with DLC $\mathrm{Chard}_{\text {was decreased to }}$ $0.1 \%$, the efficiency has increased in 1.3-1.4 times in comparison with bare solar cells [8]. The efficiency increase takes place mainly due to short circuit current increase by 1.4-1.5 times. The open circuit voltage and fill factor did not changed.

We researched the $\mathrm{DLC}_{\text {soft }}$ that have the required value of the refraction coefficient 1.9. The investigation results [9] demonstrated that $\mathrm{DLC}_{\text {soft }}$ deposition has provided the short circuit current density increasing and solar cell open circuit voltage by $42 \%$ and $12 \%$, accordingly. It were carried out the tests on many-fold temperature cycling, high

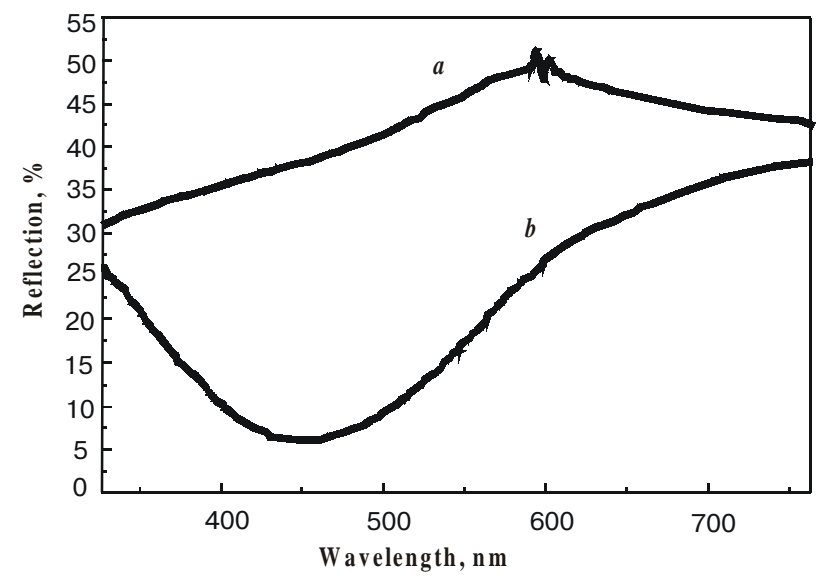

Fig.5. Solar cell reflection spectrum: (a) - bare solar cell, (b) diamond film coating with thick $0.1 \mu \mathrm{m}$ 


\section{T. V. Semikina, A. N. Shmyryeva: Optical and protective properties ...}

$(373 \mathrm{~K})$ and low $(213 \mathrm{~K})$ temperature impact, humidity $98 \%$ at temperature $308 \mathrm{~K}$ and proton influence. These tests confirmed the DLC high resistance properties. Under conditions of Earth application test AM1.5, power radiation $1000 \mathrm{~W} / \mathrm{m}^{2}, T=293 \mathrm{~K}$ our solar cells with DLC $_{\text {soft }}$ coatings had such parameters:

- open circuit voltage $U_{o c}, \mathrm{mV}$ 627

- short circuit current density $j_{s c}, \mathrm{~mA} / \mathrm{cm}^{2}$

- fill factor $F F$, rel. units

- efficiency $\eta, \%$

The solar cells radiation damages on the space orbit and gradual decrease of efficiency stem from an action of protons and electrons. The particles creating most of damages in solar cells have (before passages through solar cell coating) energy in the range from 0.2 to $1 \mathrm{MeV}$ for electrons and from 4 to $40 \mathrm{MeV}$ for protons.

The space radiation influence on solar cell parameters differs from that of initial radiation in outer space, because the initial energy spectrum and initial particles flux density undergo changes after passages through protective coatings. Under radiation impact, the solar cell coating changes its color (becomes more dark), as a consequence, the coatings absorb some larger quantity of solar illumination. The increasing absorption leads to decreasing module output power owing to decrease of illumination quantity reaching solar cell working surface and to increase of operating temperature. It resuls in decreasing efficiency of semiconductor elements owing to decreasing energy of the $p$ - $n$ junction barrier, dropping photo-electromotive force and increasing reverse current through $p$ - $n$ junction.

The solar cell current-voltage characteristics after electron irradiation are shown in Fig. 6. From represented researches, it was obtained that under high-energy electron impacts we can first of all observe short circuit current decrease. The similar behavior is typical for solar cells under some radiation impact, energy of which is enough for defect generation along all the depth of their working range. The current decrease is mainly happened as a result of carrier congregating aggravation in the long wave sensitivity range stimulated by decreasing free length $L_{b}$ in the solar cell base. The $L_{b}$ changing influences on reverse current $p$ $n$ junction value. So, the saturation current $I \sim L_{b}{ }^{-1}$, photo electromotive force of irradiated solar cell drops in $\ln L_{b}$ proportion.

During experiments we used different types of solar cell coatings: 1) $\mathrm{DLC}_{\text {soft }}$; 2) $\mathrm{DLC}_{\text {hard }}$; 3) $\mathrm{ZnS}$ films; 4) $\mathrm{TiO}_{2}$ films; 5) $\mathrm{Si}_{3} \mathrm{~N}_{4}$ films. Measured were short circuit current $I_{s c}$ and open circuit voltage $U_{o c}$ values for all solar cells with different coatings. Our results demonstrate that solar cells with $\mathrm{DLC}_{\text {hard }}$ have higher $U_{o c}$ values than for solar cell with $\mathrm{TiO}_{2}$ and were more effective as compared to solar cells with $\mathrm{Si}_{3} \mathrm{~N}_{4}$. The best samples of solar cells with $\mathrm{DLC}_{\text {hard }}$ have demonstrated the following results: $U_{o c}=0.625 \mathrm{~V}, j_{s c}=40 \mathrm{~mA} / \mathrm{cm}^{2}, F F=0.792$, $\eta=15.8 \%$ under AM0 conditions when using, irradiating power $1360 \mathrm{~W} / \mathrm{m}^{2}$ and $T=313 \mathrm{~K}$.

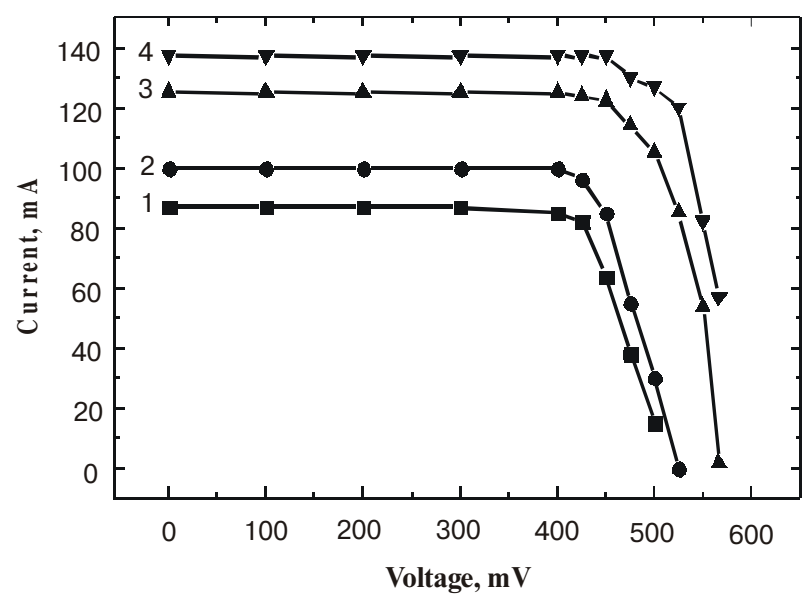

Fig.6. Load current-voltage characteristics of the solar cell under electron action with energy $1 \mathrm{MeV}$ at different electron fluxes: 1$10^{15} ; 2-10^{14} ; 3-10^{13} ; 4-10^{12} \mathrm{~cm}^{-2}$.

Solar cell tests on proton and electron impact were carried out in two regimes: 1) accelerated electron energy $E_{e}=10 \mathrm{MeV}$, electron flux density $D_{e}=5.2 \cdot 10^{11} \mathrm{~cm}^{-2} \mathrm{~s}^{-1}$, electron flux $F_{e}=1.48 \cdot 10^{14} \mathrm{~cm}^{-2}$, irradiation time $\tau=2988 \mathrm{~s}$; 2) $E_{e}=10 \mathrm{MeV}, D_{e}=1.25 \cdot 10^{10} \mathrm{~cm}^{-2} \mathrm{~s}^{-1}$, $F_{e}=1.48 \cdot 10^{14} \mathrm{~cm}^{-2}, \tau=12432 \mathrm{~s}$.

The investigation show that the solar cells with blooming $\mathrm{DLC}_{\text {hard }}$ coatings have the least degradation of parameters, while the solar cells with $\mathrm{DLC}_{\text {soft }}$ have the biggest degradation changing. After solar cells irradiation by high energy electrons, there were happened such aggravation $(\gamma)$ of solar cells parameters by: $\chi\left(U_{o c}\right)=3-10 \%$; $\chi\left(I_{s c}\right)=38-55 \% ; \chi(F F)=13-16 \% ; \gamma(\eta)=32-50 \%$. The results of studying solar cells with DLC $_{\text {soft }}$ under proton and electron irradiation represented in the work [10] pointed on good protective $\mathrm{DLC}_{\text {soft }}$ properties. The difference in obtained results could be explained by the fact that authors carried out irradiation using smaller proton energy $(50,100$ and $150 \mathrm{keV}$ ), when the pointed films kept their protective properties yet.

The largest degradation for solar cells with $\mathrm{DLC}_{\text {soft }}$ can be explained by the fact that $\mathrm{DLC}_{\text {soft }}$ film structure is rather polymer-like compound than amorphous, and these films have larger hydrogen content in their structure. That is why these films are subjects to radiation damage. Under action of high-energy electrons, the carbon-carbon and carbon-hydrogen bonds are damaged, which results in extraction of hydrogen followed by changes in optical properties ofDLC $\mathrm{Soft}_{\text {. }}$

The largest relative changes (31-54\%) are referenced to the case of short circuit current:

$\begin{array}{ll}\text { - solar cells with } \mathrm{DLC}_{\text {hard }} & 31 . . .32 \% \\ \text { - solar cells with } \mathrm{ZnS} & 37 \ldots 40 \% \text {; } \\ \text { - solar cells with } \mathrm{DLC} & 52 . .54 \%\end{array}$

The relative changes of open circuit voltage were in the range $8-11 \%$, fill factor $14-16 \%$ for all solar cell types. 


\section{T. V. Semikina, A. N. Shmyryeva: Optical and protective properties ...}

Thus, under high-energy electron irradiation the lifetime of minority carriers in a base and antireflection coating transparency decreasing are the basic degradation results.

The results of comparative analysis demonstrated that the degree of efficiency decrease for solar cells with coating based on $\mathrm{DLC}_{\text {hard }}$ (in average $32 \%$ ) is substantially smaller than for those with $\mathrm{ZnS}$ coatings ( $\sim 40 \%)$.

After proton flux impact with energy $20 \mathrm{MeV}$, it was obtained that solar cells with DLC $_{\text {hard }}$ antireflection coatings have minimum degradation degree. When proton irradiation increases more than $10^{13} \mathrm{~cm}^{-2}$, the efficiency sharply drops in average by $80-85 \%$.

\section{Conclusions}

As a results of investigations DF and DLC films prepared by laser and chemical-vapor deposition, it was obtained that indicated technological methods allow to get wide band gap films with refraction and reflection coefficients satisfying demands of blooming coatings on silicon. However, the chemical deposition method enables to directly vary values of indicated film optical parameters using selfbias voltage changing and nitrogen incorporation to gas mixture. It was found that solar cells with DLC deposited at selfbias voltage $-300 \mathrm{~V}$ and nitrogen content in the mixture within $10-15 \%$ have the optimum refraction coefficient $n=$ 1.9 and satisfy microhardness requirements. Application of these films as protective coatings against high energy proton and electron irradiation enabled to provide factor-of10-15 decrease of degradation characteristics in these solar cells in comparison with non-covered solar cells that points on good perspectives for applying such films in satellite moduli.

\section{References}

1. T. V. Semikina, A.N. Shmyrjeva, V.A. Semenovich, Photocharacteristics of a metal-carbon-silicon structure // J. Chemical Vapor Deposition. 6(2), pp. 98-103 (1997).

2. E.I. Tochitsky, O.G. Sviridovich, N.M. Beliavsky, I.V. Dudarchik, Deposition of diamond-like carbon biocompatible coating artificial heart valves // PROCEEDINGS of $4^{\text {th }}$ International Symposium on Diamond Films and Related Materials ISDF4, Kharkov, Ukraine, September 2022, pp.150-153 (1999).

3. T. Sato, S. Furuno, S. Iguchi, M. Hanabusa, Diamond-like carbon films prepared by pulsed-laser evaporation // Appl. Phys. A45, pp.355-360 (1988).

4. F.M. El-Hossary, D.J. Fabian, A.P. Webb, Optical properties of amorphous carbon films formed by r.f. plasma deposition from methane // Thin Solid Films. 192, pp.201-209 (1990).

5. V.A. Semenovich, N.I. Klyui, S.I. Frolov, V.A. Mitus. Effect of diamond-like carbon film synthesis conditions on their optical properties // STM 5, C.12-16 (1995) (in Russian).

6. V.A. Semenovich and N.I. Klyui, DLC Films: Effect of Deposition Conditions on the Optical Properties //Journal of CVD. 4(July), pp. 29-37 (1995).

7. A.G. Gontar, A.A. Doroshenko, A.M. Kutsay, S.I. Khandozhko, Synthesis and Optical Properties of (a-C:H) Diamond-Like Films for Anti-Reflection Coatings // Journal of Chemical Vapor Deposition. 4(№1), pp. 15-21 (1995).

8. L.S.Aivazova, N.V. Novikov, S.I. Khandozhko, A.G. Gontar, A.M. Kutsay, The Effect of (a-C:H) Films on the Properties of the n-Si/p-(a-SiC:H) Solar Cells // Journal of Chemical Vapor Deposition. 6(№1), pp. $52-56$ (1997).

9. A.F. Kravchenko, V.A. Semenovich, T.V. Semikina, A.N. Shmyryeva. Silicon photoelectric transducers with anti-reflecting coatings made of diamond-like carbon. In: Materials of the $6^{\text {th }}$ International Symposium "Thin films in electronics". Pt.2, p.176-177, Moscow-Kyiv-Kherson, 1995.

10. V.G. Litovchenko, N.I. Klyui, Solar cells based on DLC film - Si structures for space application // J. Solar Energy Materials and Solar Cells. 68, pp. 55-70, (2001). 